\title{
Utjecaj komine masline na okoliš
}

\author{
D. Kučić Grgić, ${ }^{a *}$ M. Gavran, ${ }^{a}$ K. Miškić, ${ }^{a}$ \\ A. Škunca a V. Ocelić Bulatovićb \\ a Fakultet kemijskog inženjerstva i tehnologije, Hrvatska \\ b Metalurški fakultet, Sveučilište u Zagrebu, Hrvatska
}

Ovo djelo je dano na korištenje pod

\begin{abstract}
Sažetak
Komina masline kao ostatna materija u prehrambenoj industriji ne ubraja se u opasni otpad ili otpad općenito. To je potencijalni problem zbog njezinih određenih komponenata koje negativno utječu na ekosustav, a osobito na vodene organizme i biljke. Uslijed neadekvatnog odlaganja, spojevi komine bivaju isprani i procjeđivanjem dospijevaju u tla i podzemne vode gdje uzrokuju onečišćenja. Tema privlači dodatan interes zbog potencijala iskorištavanja komine masline u raznorazne svrhe, te je predmet mnogih znanstvenih istraživanja današnjice.
\end{abstract}

Ključne riječi

Komina masline, otpad, toksičnost, sirovina

\section{Uvod}

Maslina je vrlo stara biljna vrsta koja se prije 5 do 6 tisuća godina s područja Mezopotamije, Sirije i Palestine proširila Mediteranom, gdje se danas najviše uzgaja. ${ }^{1}$ Zbog minimalnih zahtjeva održavanja, visoke prehrambene vrijednosti i velike tolerancije na sušu maslina je jedna od najobrađivanijih kultura u svijetu. ${ }^{2}$ Od procijenjenih 900 milijuna stabala, gotovo $98 \%$ uzgaja se u mediteranskom području. ${ }^{3}$ Stoga su masline kao i maslinovo ulje karakteristični za mediteransku prehranu te je dokazana povezanost s pozitivnim utjecajem na zdravlje srca i smanjenje pojave raka prostate, dojke i debelog crijeva. ${ }^{4}$

Maslina (Olea europea) uspijeva na krševitu tlu, a s obzirom na to da ne podnosi niske temperature, u Hrvatskoj se uzgaja u priobalju. To je zimzelena biljka visine do $10 \mathrm{~m}$, a promjer debla doseže do $1 \mathrm{~m}$. Listovi su svijetlozeleni, mali, duguljasti, kožasti, a plod uslijed sazrijevanja mijenja boju iz zelene u ljubičastu, gotovo crnu boju pri čemu se gubi gorčina i povećava se sadržaj ulja. ${ }^{1}$ Zeleni plodovi beru se za jelo, dok se preradom zrelih, ljubičastih plodova dobiva maslinovo ulje. Plod masline sastoji se od kožice, pulpe i sjemenke. Ulje u plodu masline nalazi se u pulpi i to u vakuolama unutar stanica. ${ }^{5}$

Plodovi maslina nakon dopremanja u uljaru prolaze kroz proces čišćenja i pranja te slijedi mljevenje da bi se ulje oslobodilo iz vakuola pulpe ploda. Kako bi se kapljice ujedinile u veće, provodi se miješanje maslinova tijesta dobivenog mljevenjem, nakon čega slijedi ekstrakcija ulja, koja se temelji na jednom od tri principa: prešanju, centrifugiranju ili selektivnoj filtraciji. ${ }^{6}$

Preradom maslina nastaju velike količine tekućeg i krutog otpada, odnosno nastaje otpadna voda te komina masline, koji predstavljaju velik ekološki problem u sredozemnim

*Autor za dopisivanje: doc. dr. sc. Dajana Kučić Grgić e-pošta: dkucic@fkit.hr zemljama EU-a. Otpadna voda iz procesa prerade i komina masline može sadržavati fitotoksične spojeve poput fenola, patogene mikroorganizme kao i visok sadržaj lipida i organskih spojeva, što može rezultirati onečišćenjem okoliša ukoliko se ne zbrinjavaju na pravilan način. ${ }^{7}$

U Hrvatskoj, proizvođači maslinova ulja su najčešće mala i srednja obiteljska poljoprivredna gospodarstva (OPG) s ograničenim pristupom informacijama o gospodarenju otpadom te manjim mogućnostima ulaganja u njegovo zbrinjavanje. S obzirom na pozitivan trend proizvodnje maslinova ulja i sve restriktivnije zakonodavstvo o okolišu, potrebno je istražiti nove načine zbrinjavanja te vrste otpada.

\section{Teorijski dio}

\subsection{Proces proizvodnje maslinova ulja}

U modernom maslinarstvu berba započinje pri optimalnoj zrelosti koja se može odrediti na razne načine, a najčešće se temelji na stupnju pigmentacije ploda (pokožice i pulpe). Uglavnom se s berbom počinje prije no što su svi plodovi potpuno zreli (slika 1). U svrhu ekstrakcije maslinova ulja primjenjuju se diskontinuirani (prešanje) ili kontinuirani procesi (centrifugiranje) (slika 2). ${ }^{8,9}$ Nakon što se plod samelje nastala pasta se miješa kako bi se povećao postotak dostupnog ulja i kako bi se aglomerirale male kapljice ulja za lakše razdvajanje uljne i vodene faze. Ono što je bitno naglasiti da i sam plod od masline sadrži visok udio vode, što znatno pridonosi povećanju volumena otpadnih voda.

Najstariji i najčešće primjenjivani postupak prerade masline je prešanje. Pasta masline koja se dobije drobljenjem nanosi se na diskove od sintetičkih vlakana koji se stavljaju u hidrauličnu prešu. Na njih se vrši pritisak prešom da bi se čvrsta faza maslinove paste zbila. Komina koja sadrži pulpu masline, kožu, koštice i vodu zaostaje na disku, dok se 


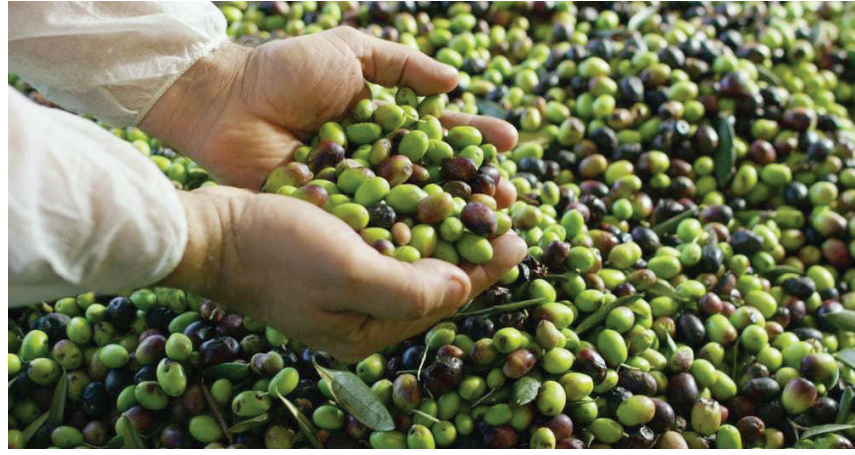

Slika 1 - Plod masline ${ }^{9}$

Fig. 1 - Olives $^{9}$

mješavina maslinova ulja i zaostale vode u sljedećem koraku odvaja pomoću uljnog separatora radi razdvajanja ulja od vode. Prednost te metode je jeftina oprema i tehnička jednostavnost, međutim diskontinuiranost procesa i visoki troškovi rada kao i veći KPK nastale otpadne vode neki su od nedostataka te metode. ${ }^{3}$

Kontinuirani proces ekstrakcije maslinova ulja također započinje drobljenjem ploda masline kako bi se dobila maslinova pasta te se primjenom centrifuge iz maslinove paste separira maslinovo ulje, voda i komina. Kod kontinuiranog procesa razlikuju se dvofazni i trofazni sustav ekstrakcije.

Kod centrifugalne ekstrakcije u tri faze, na stupnju centrifugiranja dodaje se voda, zbog čega kao nusprodukt nastaju veće količine otpadne vode. Također, osim otpadne vode, trofaznim sustavom nastaje i kruti ostatak, odnosno komina te ulje kao tekuća faza. Taj sustav ima mnogo prednosti, kao što su potpuna automatizacija i bolja kvaliteta ulja, no visoki inicijalni troškovi, velika potrošnja vode i energije, kao i veća količina otpadne vode koja nastaje nedostatci su tog postupka. Bez obzira na to, taj postupak i dalje je najzastupljeniji jer se u manjem razdoblju mogu dobiti veće količine maslinova ulja. ${ }^{3}$ Kako bi se smanjio utjecaj na okoliš, otpadna voda iz centrifugalne ekstrakcije u tri faze može se skladišti u bazenima za isparavanje te se izravno rabiti u poljoprivredi kao gnojivo. S ciljem smanjenja volumena otpadne vode razvijen je proces centrifugalne ekstrakcije u dvije faze. Na taj se način maslinova pasta dijeli u dvije faze: maslinovo ulje i vlažnu kominu kao polučvrsti otpad, koji se sastoji od krutog ostatka i otpadne vode. Takav način prerade maslina dominantan je u Španjolskoj a široko je rasprostranjen i u Hrvatskoj. ${ }^{3}$

U tablici 1 prikazani su glavni parametri za različite postupke dobivanja maslinova ulja. Vidljivo je da se iz svakog procesa dobije oko 20 \% maslinova ulja, dok se dobivena količina komine i otpadne vode razlikuje za svaki proces.

Proizvodnja maslinova ulja, sa strane potrošnje energije i kemikalija, ekološki je prihvatljiva, međutim pri samoj proizvodnji generiraju se velike količine krutog i tekućeg otpada, a mogućnosti zbrinjavanja takve vrste otpada posljednjih desetljeća intenzivnije se istražuju. ${ }^{12}$

\subsection{Sastav i svojstva otpadne vode i komine masline}

Kao što je već spomenuto, prilikom prerade maslina, nastaje tekući i kruti otpad, odnosno otpadna voda i komina masline. Kemijski sastav nastale otpadne vode i komine masline ovisi o vrsti masline, uvjetima uzgoja, porijeklu masline te o vrsti ekstrakcije. ${ }^{3}$

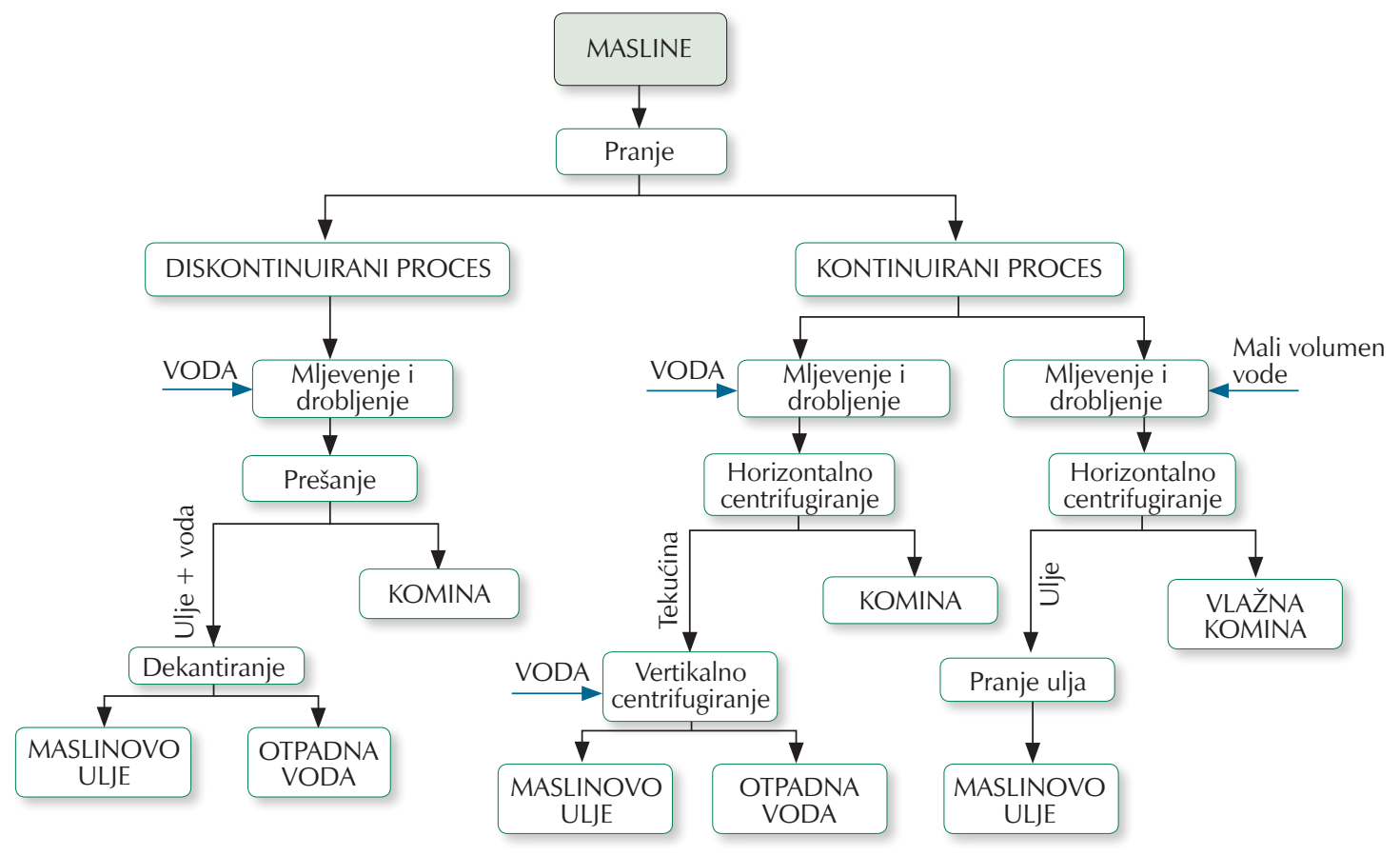

Slika 2 - Kontinuirani i diskontinuirani proces ekstrakcije maslinova ulja ${ }^{3}$

Fig. 2 - Continuous and discontinuous olive oil extraction process ${ }^{3}$ 
Tablica 1 - Ulazno-izlazni podatci za tri različita postupka proizvodnje maslinova ulja ${ }^{10,11}$

Table 1 - Input-output data for three different processes of olive oil production ${ }^{10,11}$

\begin{tabular}{|c|c|c|c|c|}
\hline Proizvodni proces & Ulaz & Količina na ulazu & Izlaz & Količina na izlazu / kg \\
\hline \multirow{3}{*}{ diskontinuirani proces } & masline & $1 \mathrm{t}$ & ulje & $\sim 200$ \\
\hline & voda za pranje & $0,1-0,12 \mathrm{~m}^{3}$ & komina & $\sim 400$ \\
\hline & energija & $40-63 \mathrm{kWh}$ & otpadna voda & $\sim 600$ \\
\hline \multirow{4}{*}{ centrifugalna ekstrakcija u tri faze } & masline & $1 \mathrm{t}$ & ulje & 200 \\
\hline & voda za pranje & $0,1-0,12 \mathrm{~m}^{3}$ & komina & $500-600$ \\
\hline & voda za centrifugiranje & $0,5-1 \mathrm{~m}^{3}$ & \multirow{2}{*}{ otpadna voda } & \multirow{2}{*}{$1000-1200$} \\
\hline & energija & $90-117 \mathrm{kWh}$ & & \\
\hline \multirow{3}{*}{ centrifugalna ekstrakcija u dvije faze } & masline & $1 \mathrm{t}$ & ulje & 200 \\
\hline & voda za pranje & $0,1-12 \mathrm{~m}^{3}$ & \multirow{2}{*}{ komina } & \multirow{2}{*}{$800-950$} \\
\hline & energija & $90-117 \mathrm{kWh}$ & & \\
\hline
\end{tabular}

Otpadna voda dobivena preradom maslina je crveno-crne boje, niske pH-vrijednosti, visoke vodljivosti i visokog organskog opterećenja. Glavni spojevi prisutni u otpadnoj vodi su voda, fenoli, šećeri, organske kiseline te mineralne hranjive tvari. ${ }^{8}$

Komina masline dobivena centrifugalnom ekstrakcijom u dvije faze znatno se razlikuje od komine masline dobivene prešanjem i centrifugalnom ekstrakcijom u tri faze. To je gusti mulj koji sadrži koštice i pulpu masline te otpadnu vodu. Fizikalno-kemijskom analizom (tablica 2) ustanovljeno je da komina ima visok udio vode ( $w=55,6-74,5 \%$ ), blago je kisela, pH vrijednosti $(4,8-6,5)$ te ima vrlo visok udio organske tvari. Glavni spojevi koji se nalaze u komini masline su celuloza, hemiceluloza, lignin, masti i proteini. Među mineralnim tvarima u sastavu komine ističu se kalij, kalcij i natrij te uglavnom organski dušik, ali je siromašna fosforom i mikronutrijentima. ${ }^{10}$

\subsubsection{Ekotoksičnost}

S obzirom na visok sadržaj fenola, lipida i ostalih organskih spojeva, i otpadna voda i komina masline dokazanog su fitotoksičnog djelovanja, dakle imaju negativne učinke na tlo. ${ }^{12}$ Fitotoksičnost komine procjenjuje se s obzirom na dvije različite tehnologije centrifugiranja, odnosno centrifugalna ekstrakcija u dvije faze i tri faze. ${ }^{13}$ Prema literaturi, komina masline iz centrifugalne ekstrakcije u dvije faze može sadržavati veću koncentraciju fenolnih spojeva od dobivene komine u centrifugalnoj ekstrakciji u tri faze, a također je zabilježeno nastajanje fitotoksičnije komine centrifugalnom ekstrakcijom u dvije faze. ${ }^{13,14}$ Za procjenu fitotoksičnosti najčešće se provodi biološki test s Lepidium sativum L. zbog brzog odgovora, velike osjetljivosti i isplativosti. Najštetniji utjecaj fenola očituje se u smanjenju korijena od $50 \%$ u odnosu na kontrolu pri koncentraciji od $75 \mathrm{mgl}^{-1} .{ }^{14}$ Također, ustanovljeno je inhibicijsko djelovanje fenola na klijanje i rast testne biljke Lactuca sativa, letalan utjecaj na vrstu Artemia salina te genotoksičan učinak na Allium cepa. ${ }^{15}$ Nadalje, na tlu opterećenom otpadom od masline dokazano je smanjenje enzimske djelotvornosti, osobito za fosfatazu i fluorescein diacetat hidrolazu. ${ }^{16}$
Tablica 2 - Fizikalno-kemijski sastav komine masline $\mathrm{e}^{10}$ Table 2 - Physicochemical composition of olive pomace ${ }^{10}$

\begin{tabular}{|c|c|}
\hline Parametri & Komina \\
\hline vlaga $/ \%$ & $55,6-74,5$ \\
\hline $\mathrm{pH}$ & $4,86-6,45$ \\
\hline električna vodljivost / $\mathrm{dS} \mathrm{m}^{-1}$ & $0,88-4,76$ \\
\hline pepeo $/ \mathrm{g} \mathrm{kg}^{-1}$ & $24,0-151,1$ \\
\hline ukupni organski ugljik, TOC $/ \mathrm{g} \mathrm{kg}^{-1}$ & $495,0-539,2$ \\
\hline$C: N$ omjer & $28,2-72,9$ \\
\hline ukupni dušik/g kg & $7,0-18,4$ \\
\hline organska tvar $/ \mathrm{g} \mathrm{kg}^{-1}$ & $848,9-976,0$ \\
\hline lignin / $\mathrm{g} \mathrm{kg}^{-1}$ & $323,0-556,5$ \\
\hline hemiceluloza / $\mathrm{g} \mathrm{kg}^{-1}$ & $273,0-415,8$ \\
\hline celuloza $/ \mathrm{g} \mathrm{kg}^{-1}$ & $140,2-249,0$ \\
\hline lipidi / g kg-1 & $77,5-194,6$ \\
\hline proteini $/ \mathrm{g} \mathrm{kg}^{-1}$ & $43,8-115,0$ \\
\hline $\mathrm{P} / \mathrm{g} \mathrm{kg}^{-1}$ & $0,7-2,2$ \\
\hline $\mathrm{K} / \mathrm{g} \mathrm{kg}^{-1}$ & $7,7-29,7$ \\
\hline $\mathrm{Ca} / \mathrm{g} \mathrm{kg}^{-1}$ & $1,7-9,2$ \\
\hline $\mathrm{Mg} / \mathrm{g} \mathrm{kg}^{-1}$ & $0,7-3,8$ \\
\hline $\mathrm{Na} / \mathrm{g} \mathrm{kg}^{-1}$ & $0,5-1,6$ \\
\hline $\mathrm{Fe} / \mathrm{mg} \mathrm{kg}^{-1}$ & $78,9-1462,0$ \\
\hline $\mathrm{Cu} / \mathrm{mg} \mathrm{kg}^{-1}$ & $12,0-29,0$ \\
\hline $\mathrm{Mn} / \mathrm{mg} \mathrm{kg}^{-1}$ & $5,0-39,0$ \\
\hline $\mathrm{Zn} / \mathrm{mg} \mathrm{kg}^{-1}$ & $10,0-37,0$ \\
\hline
\end{tabular}


Ekotoksikološki testovi provedeni na otpadnim vodama dokazali su njihovu visoku akutnu toksičnost. Konkretnije, za makrobeskralježnjake Gammarus pulex i Hydropsyche peristerica zabilježene su letalne doze $\left(\mathrm{LD}_{50}\right)$ od 2,6 \% do 3,8 \%; za mikrobeskralježnjake Daphnia magna i Thamnocephalus platyurus LD $_{50}$ vrijednosti iznosile su između $0,7 \%$ i $12,4 \%$; za luminscentnu bakteriju Vibrio fischeri određena je efektivna koncentracija $\left(E_{50}\right)$ od $0,2 \%$ do $1,2 \% .{ }^{17-19} \mathrm{~S}$ obzirom na manjkavost provedenih ekotoksikoloških testova na tlu onečišćenim sirovim otpadom masline, grubo se zaključilo da tako opterećeno tlo ima smanjenu mikrobiološku aktivnost i da je na njima otežan rast i razvoj biljaka. Istraživanja su većinom provedena na tlu koje je obrađeno kompostom dobivenim od ostataka maslina. ${ }^{20-24}$ Pardo i sur. su od 2011. do 2014. opisali sniženje izravne i neizravne fitotoksičnosti za Lactuca sativa, Lolium perenne, Zea mays i Lactuca sativum nakon tretiranja gnojivom komine masline. ${ }^{21-24}$ Ispitivanja su provedena na laboratorijskoj skali, u staklenicima i na otvorenim poljima. Kod svih provedenih ispitivanja gnojivo je imalo pozitivan učinak na dostupnost nutrijenata, povećana je $\mathrm{pH}$ vrijednost tla te je topljivost čestica prisutnih u tragovima (Cu, Pb, Fe), koje predstavljaju prepreku za uravnotežen razvoj flore i fauna na cjelokupnom onečišćenom području, smanjena. Nadalje, pomoću organizma T. Platyurus i mikroorganizma V. Fisheri dokazano je znatno smanjenje toksičnosti tla nakon dodatka komposta od komine masline, kako za kratko (4,5 mjeseci) tako i za dugo (2,5 godina) razdoblje, što je u skladu s objavljenom literaturom. ${ }^{20}$ Beesley $i$ sur. opisali su značajan pad topljivosti metala u tragovima, što je za posljedicu imalo smanjenje toksičnosti tla na vrste L. Sativum i V. Fisheri. Beesleyjeva studija također je potvrdila neovisnost uporabe biougljena, jer su jednako dobri rezultati prikupljeni sa i bez njegove upotrebe. Da je uporaba biougljena korisna za smanjenje koncentracije metala u tragovima spominju i drugi autori. ${ }^{25}$ Međutim, daljnja istraživanja su pokazala da biougljen naglo mijenja $\mathrm{pH}$ tla, što u kombinaciji s mogućom ingestijom negativno utječe na određene biljne i životinjske vrste. Provedena su istraživanja na kišnoj glisti, Eisenia foetida, koja je podnosila kratkotrajne negativne učinke na preživljavanje, rast i razmnožavanje. ${ }^{26,27} \cup$ drugu ruku, biougljen na bazi masline djelovao je potpuno suprotno na glistu. U 120 dana nije zabilježen niti jedan toksični učinak, štoviše, postignuta je stopa preživljavanja od 100 \%. Za usporedbu, stopa preživljavanja gliste u netretiranom tlu bila je 12,3 \%. Nadalje, zabilježen je značajan rast glista te je povećan broj larvi. Zaključno, provedena su ispitivanja s različitim udjelom biougljena, $5 \%$, $10 \%$ i $15 \%$, a rezultati nisu pokazali ovisnost navedenih pozitivnih učinaka o udjelu biougljena. ${ }^{25}$

\subsection{Primjena komine masline}

Jedna od glavnih zadaća u agrokulturi za ispunjenje načela cirkularne ekonomije je smanjenje i iskorištavanje biljnih ostataka. Zavisno o vrsti i uspješnosti procesa, pri obradi poljoprivrednih kultura zaostaje više ili manje ostatka, što je u slučaju prerade masline komina masline i otpadna voda. Procjena količine otpada koji nastaje u proizvodnji maslinova ulja u EU-u je oko 6,8 milijuna tona godišnje. U Hrvatskoj se proizvodi oko 30000 tona maslina godišnje, pri čemu nastaje oko 12000 tona komine. ${ }^{6}$ Da je navede- ne ostatke izrazito bitno iskorištavati, a ne odlagati, potvrđuju razna istraživanja kojima je cilj bio utvrditi isplativost i učinkovitost metoda obrade otpada od proizvodnje maslinova ulja. Uz to, otpadna voda i komina masline predstavljaju ekološki problem zbog visokog organskog opterećenja, niskog $\mathrm{pH}$ te visoke koncentracije fenola. Komina masline u Hrvatskoj slabo se iskorištava jer nije prepoznat njezin sirovinski potencijal te najčešće završava kao otpad uzrokujući onečišćenje tla, a posljedično i voda. Stoga se moraju pronaći tehnološka rješenja za njezino zbrinjavanje. ${ }^{28}$

Komina masline zbog dobrih termokemijskih karakteristika pruža mogućnost potencijalnog iskorištavanja u energetske svrhe istodobno rješavajući i problem nepravilnog odlaganja. ${ }^{29}$ Komina ima visok sadržaj organske tvari i minerala, osim sumpora, koji predstavljaju moguć izvor hranjivih tvari za rast i razvoj biljaka, stoga se kao jedan od ekološki najprihvatljivijih načina zbrinjavanja nameće kompostiranje. Drugi vrijedni spojevi prisutni u komini masline su polifenoli, koji zbog antioksidativnog djelovanja pokazuju zaštitni učinak na DNK zbog čega je moguća njihova primjena u kremama i drugim proizvodima za osobnu higijenu. ${ }^{30}$ Nadalje, potencijalni način pravilnog zbrinjavanja tog vrijednog otpada jest implementacija u polimernu industriju kao punila u polimernim materijalima.

\subsubsection{Komina masline kao izvor energije}

S obzirom na ograničenje postojećih naftnih rezervi i negativan utjecaj fosilnih goriva na okoliš, nužan je razvoj ekonomski isplativih, ekološki prihvatljivih, obnovljivih i dostupnih tzv. alternativnih izvora energije. ${ }^{31}$ Prema Međunarodnoj agenciji za energiju (engl. International Energy Agency, IEA) potrebna je postupna zamjena fosilnih goriva odgovarajućim alternativnim gorivima, dok je Europska unija postavila cilj povećanja proizvodnje energije iz alternativnih izvora s $20 \%$ na $27 \%$ do 2030. godine (obnovljiva energija može se proizvesti iz raznih izvora, uključujući biomasu, vjetar, solarnu energiju, hidroenergiju, geotermalnu, itd.). ${ }^{31}$

Kao vrijedan izvor obnovljive energije ističe se biomasa, posebice ukoliko se dobiva iz otpada, kao što je primjerice komina masline. Komina masline ima znatnu energetsku vrijednost, što otvara mogućnost uporabe u energetske svrhe. Bruto kalorijske vrijednosti u rasponu su od 19,815 do 24,455 MJ kg-1, dok je srednja kalorijska vrijednost oko $21,645 \mathrm{MJ} \mathrm{kg}^{-1} \cdot 32,33$

Energija iz komine masline može se dobiti anaerobnom digestijom te sagorijevanjem u pećima za biomasu. Komina masline se također može pretvoriti u tekuće gorivo, biodizel.

Anaerobna digestija je proces mikrobiološke razgradnje koju provode anaerobni i fakultativno anaerobni mikroorganizmi te se odvija u četiri stupnja: hidroliza makromolekula; acidogeneza; acetogeneza i metanogeneza. ${ }^{34}$ Krajnji produkt anaerobne razgradnje je bioplin, smjesa metana volumnog udjela ( $\varphi=55-75 \%$ ) i ugljikova dioksida volumnog udjela ( $\varphi=25-45 \%$ ). Također, nastaje stabilizirani mulj pogodan za ponovnu upotrebu kao gnojivo zemljišta. 
Komina masline ne može se sama tretirati pod anaerobnim uvjetima jer u takvom načinu primjene komine, prisutni polifenoli imaju inhibicijski učinak na proces zbog čega se komina ispire i razrjeđuje otpadnom vodom. ${ }^{35}$ Prednost anaerobne digestije $u$ vidu zbrinjavanja jest $u$ tome što se istodobno tretira i kominu i otpadnu vodu. Međutim, nedostatci anaerobnog tretiranja otpadnih tokova iz postrojenja za preradu masline odnose se na ekonomsku isplativost s obzirom na teritorijalno raspršenje te sezonsko djelovanje postrojenja za proizvodnju maslinova ulja. ${ }^{36}$

Komina se u Hrvatskom priobalju dugo rabila kao ogrjevno sredstvo te se zajedno s drvetom ubacivala u kućno ognjište, a danas se energija iz komine termokemijski dobiva sagorijevanjem peleta u pećima za proizvodnju energije, pri čemu dobiveni vrući plinovi pokreću kogeneracijsko postrojenje za dobivanje električne i toplinske energije. Peletiranje je termoplastični proces u kojem se sirovina zbija s vezivom i formira cilindrični oblik, tzv. pelet. Prednost peleta je njihova kompaktnost zbog čega su jednostavni za rukovanje, a zbog smanjenog sadržaja vlage imaju veću ogrjevnu vrijednost. Termokemijska obrada komine je $\mathrm{CO}_{2}$ neutralan proces jer biomasa tijekom svojeg rasta apsorbira određenu količinu ugljikova dioksida koji se spaljivanjem ponovno emitira u zrak. ${ }^{6}$

Među različitim alternativnim izvorima energije, biogoriva dobivena iz biomase dobila su više interesa budući da se mogu upotrebljavati kao transportna goriva te pružaju energetsku neovisnost i sigurnost, a uz to stvara se znatno manje $\mathrm{CO}_{2}$ (sagorijevanjem biodizela u atmosferu vraća se onaj $\mathrm{CO}_{2}$, koji je u procesu fotosinteze biljka iz atmosfere uzela pa ne dolazi do stvaranja novog $\mathrm{CO}_{2}$ ) i drugih stakleničkih plinova. ${ }^{31}$ Prva generacija biogoriva proizvedena iz prehrambenih sirovina ne može se više ubrajati u prihvatljive alternativne oblike energije, u koje spadaju samo napredne generacije biogoriva (koje za sirovinu ne upotrebljavaju prehrambene sirovine, već otpadne tvari), s obzirom na preusmjeravanje politike poticanja na europskoj razini isključivo na takva biogoriva. ${ }^{37}$ Najperspektivnije biogorivo koje zamjenjuje petrodizel je biodizel, a može se proizvesti od raznih biljnih ulja i životinjskih masti procesom transesterifikacije. Kako bi se sintetizirao biodizel, iz komine masline potrebno je ekstrakcijom odvojiti ulje, dok se ostatak može rabiti u različite svrhe primjerice proizvodnju peleta za grijanje, kompost i proizvodnju električne energije. ${ }^{38}$

\subsubsection{Kompostiranje komine masline}

Kompostiranje je biokemijski proces aerobne razgradnje organskog otpadnog materijala. U prikladnim uvjetima, kompostiranje ima tri uzastopne faze: početna faza aktivacije, termofilna faza prepoznata naglim porastom temperature, i mezofilna faza gdje se organski materijal hladi na temperaturu okoliša. ${ }^{39}$ Metabolička aktivnost mikroorganizama stvara toplinu koja dovodi do fizikalno-kemij- skih promjena organskih tvari u biomasu, $\mathrm{CO}_{2}$ i humus te na kraju procesa stabilnu, kompleksnu mješavinu bogatu hranjivim tvarima. Otpad nastao proizvodnjom maslinova ulja u mediteranskim zemljama, vrlo je fitotoksičan i sadrži fenolne spojeve, lipide i organske kiseline koji negativno utječu na ravnotežu okoliša. Također sadrži visok postotak organskih tvari i širok raspon biljnih hranjivih tvari koje se mogu iskoristiti i upotrijebiti kao gnojivo u poljoprivredni. Kompostiranje je prikladna, ekonomski i ekološki prihvatljiva tehnologija za male ili srednje velike proizvodne procese prerade masline $(<1000 \mathrm{t})$ čiji bi se produkt mogao rabiti u poljoprivredi kao ekološki prihvatljivo gnojivo. ${ }^{40}$

Prostor u kojem se želi proizvesti ekološki maslinarski otpad iz komine masline potrebno je ograditi kamenom ili nekim drugim materijalom koji je dostupan u obliku izduženog pravokutnika ili trapeza u veličini koja je potrebna. Ograda služi kako se sirovina ne bi prosipala izvan prostora, idealno bi bilo da je prostor u sjeni, odnosno što kraće izložen suncu.

Tijekom procesa kompostiranja u biomasi se javljaju složene interakcije između fizikalnih, kemijskih i bioloških procesa. Čimbenici kao što su temperatura, pH, električna vodljivost (EC), vlaga, gustoća, poroznost, veličina čestica, organski sadržaj ugljika (C), dušika $(\mathrm{N})$, omjer ugljik prema dušiku (C/N) i opskrba kisikom pokazali su se ključnim elementima za vođenje i poboljšanje procesa kompostiranja, budući da reguliraju uvjete rasta i razvoja mikroorganizama te razgradnju organske tvari $(\mathrm{OM}) .{ }^{41}$

Temperaturom se kontrolira biorazgradnja organskog materijala te na nju utječe niz drugih parametara kao što su volumen organskog materijala, prozračivanje, kompostna poroznost i vlaga. Idealan raspon temperature za kompostiranje tijekom termofilne faze je $40-65{ }^{\circ} \mathrm{C}$, a temperatura iznad $55{ }^{\circ} \mathrm{C}$ je potrebna kako bi se uništili patogeni mikroorganizmi prisutni u biomasi. Uz temperaturu treba obratiti pažnju i na aeraciju kompostne mase koja može biti u obliku mehaničkog miješanja ili prisilne aeracije. ${ }^{40}$

Lako razgradljivi organski spojevi, kao što su jednostavni ugljikohidrati, masti i aminokiseline, brzo se razgrađuju na početku procesa, dok se otporniji i složeniji organski supstrati kao što su celuloza, hemiceluloza i lignin djelomično razgrađuju i polako transformiraju u jednostavnije spojeve. Sadržaj organske tvari u kompostu ovisi o prirodi materijala koji se upotrebljava, kao i o aktivnosti mikroorganizama prisutnih u kompostu. Ostale tvari koje su inače prisutne u komini masline su fenolni spojevi. Fitotoksičnost tih spojeva je posebno zabrinjavajuća. Tijekom termofilne faze kompostiranja sadržaj fenola se znatno smanji i do kraja procesa kompostiranja neznatno se mijenja. Krajnji produkt - kompost sadrži $93 \%$ manje fenola. ${ }^{42}$

Tablica 3 prikazuje fizikalno-kemijska svojstva (organska tvar, pH, EC i C/N omjer) komposta dobivenog iz komine masline i otpadne vode nastalih proizvodnjom maslinova ulja. $^{40}$ 
Tablica 3 - Fizikalno-kemijska svojstva komposta komine masli$\mathrm{ne}^{40,43}$

Table 3 - Physicochemical properties of olive pomace compost $^{40,43}$

\begin{tabular}{l|c|c}
\hline Svojstva & $\begin{array}{c}\text { Početna } \\
\text { vrijednost }\end{array}$ & $\begin{array}{c}\text { Konačna } \\
\text { vrijednost }\end{array}$ \\
\hline $\mathrm{pH}$ & $6,4-6,6$ & $8,5-8,7$ \\
\hline električna vodljivost $(\mathrm{EC}) / \mathrm{dSm}^{-1}$ & 0,7 & $0,03-0,46$ \\
\hline organska tvar $(\mathrm{OM}) / \%$ & $70-81$ & $47-48$ \\
\hline $\mathrm{C} / \mathrm{N}$ omjer & $31-32$ & $14-17$ \\
\hline
\end{tabular}

Iz tablice 3 se vidi da se procesom kompostiranja $\mathrm{pH}$ vrijednost povećava, dok se električna vodljivost (EC) koja je odraz topljivih soli prisutnih u kompostnoj mješavini smanjuje. Tijekom biooksidacijske faze u procesu kompostiranja, organski se ugljik smanjuje u supstratnom materijalu. Tim procesom se dobivaju konačni proizvodi koji su bogati hranjivim tvarima te služe kao gnojiva za usjeve.

Pokazalo se da kompostiranjem otpada iz procesa proizvodnje maslinova ulja nastaje visoko kvalitetan kompost bez patogenih mikroorganizama. Mehaničko okretanje je dobar način prozračivanja komposta što se tiče troškova, dok se prilikom prisilne aeracije troši električna energija i time povećavaju operativni troškovi procesa. Maslinarski kompost odavno je poznat u svijetu, ali je tek nedavno poprimio velik broj pristaša među maslinarima, koji se zbog sve skupljih mineralnih gnojiva, ali i radi prelaska na ekološku proizvodnju ulja priklonili proizvodnji vlastitog komposta. U Brodarici nedaleko od Šibenika maslinari nakon berbe maslina i proizvodnje maslinova ulja kompostiraju taj dragocjeni otpad te ga rabe kao gnojivo za masline i vinovu lozu. Mikroorganizme koji sudjeluju u procesu kompostiranja treba temeljito proučiti kako bismo bolje razumjeli i unaprijedili proces kompostiranja te smanjili štetan utjecaj komine masline i otpadne vode na okoliš. ${ }^{40}$

\subsubsection{Kozmetički proizvodi}

Koža je najveći ljudski organ i služi kao štit od utjecaja okoliša, konkretnije, štiti organizam od ultraljubičastog zračenja i onečišćujućih tvari u zraku. Takva izloženost škodi stanicama kože, dolazi do formiranja radikala koji kemijskim reakcijama uzrokuju negativne promjene na koži, posebice ubrzano starenje. ${ }^{44}$

Glavni cilj kozmetičke industrije je usporiti starenje kože što iz zdravstvenih, što iz estetskih razloga. Potrošači danas osim estetskog i zdravstvenog zadovoljstva teže uporabi prirodnih preparata. Komina masline sadrži mnogobrojne spojeve koji pozitivno utječu na kožu koji su prikazani u tablici 4.

Pri izradi proizvoda za njegu tijela izrazito je važno antioksidantivno svojstvo komine. Fenoli su prirodni antioksidansi koji u prisustvu kisika, vodikova peroksida i raznih radikala sprječavaju reakcije peroksidacije, koje su smatrane jednim od glavnih faktora kod starenja kože. ${ }^{44-46}$
Tablica 4 - Utjecaj spojeva prisutnih u komini masline na kožu 45,46 Table 4 - Effect of the compounds present in olive pomace on the $\operatorname{skin}^{45,46}$

\begin{tabular}{l|l}
\hline \multicolumn{1}{c|}{ Ime spoja } & \multicolumn{1}{c}{ Utjecaj na kožu } \\
\hline $\begin{array}{l}\text { celuloza } \\
\text { peptični polisaharid } \\
\text { hemicelulozni polimer }\end{array}$ & $\begin{array}{l}\text { - poboljšavanje fizikalnih i } \\
\text { strukturnih svojstava pri hidrataciji } \\
\text { - povećavanje kapaciteta } \\
\text { zadržavanja ulja }\end{array}$ \\
\hline \multirow{2}{*}{ skvalen } & $\begin{array}{l}\text { - omekšava kožu } \\
\text { - potiče izdvajanje ksenobiotika iz } \\
\text { organizma }\end{array}$ \\
\hline \multirow{2}{*}{ fenoli } & $\begin{array}{l}\text { - antioksidativna svojstva } \\
\text { - antiupalna svojstva }\end{array}$ \\
\hline
\end{tabular}

Koliko je prepoznat kozmetički potencijal komine u Hrvatskoj pokazuje Neva Jurman sa svojim radom "Postupak dobivanja zdravstveno ispravnog aktivnog elementa od komine masline za upotrebu u kozmetici". Riječ je o inovaciji za koju je 2014. dobila razna međunarodna priznanja, među ostalim i nagradu Glory medal za doprinos ekologiji. U njezinom radu je višestruko isticano trostruko djelovanje komine na kožu. Njezini proizvodi "Brides \& Virgins" i "45 stupnjeva" dokazano sprječavaju prerano starenje kože uzrokovano oksidativnim stresom, olakšavaju zadržavanje tekućine u epidermalnom sloju kože, čime se sprječava transepidermalni gubitak vode u tkivu te služe kao zaštita koži zbog svojih protuupalnih, antialergijskih i antibakterijskih svojstava. ${ }^{47}$

\subsubsection{Komina u polimernoj industriji}

Polimerni materijali imaju široku upotrebu u svakodnevnom životu. Glavna su sirovina u industriji obuće i odjeće, upotrebljavaju se za izradu sportske opreme, digitalno elektroničkih uređaja, u prehrambenoj industriji kao ambalaža, u medicini za izradu leća, zubi, umjetnih kukova, katetera, u farmaceutskoj industriji pri proizvodnji kapsula za lijekove, u kozmetičkoj i građevinskoj industriji te za proizvodnju raznih dijelova automobila i ostalih vozila. ${ }^{48-50}$ S obzirom na to da je sirovina za njihovo dobivanje neobnovljivo fosilno gorivo i da u velikoj mjeri onečišćuju okoliš, početkom ovog stoljeća porasla je osviještenost o potrebi za alternativnim materijalima koji će biti prirodnog podrijetla sa smanjenim negativnim utjecajem. U skladu s politikom očuvanja okoliša, cirkularne ekonomije i održivog razvoja radi se na istraživanju i implementaciji punila prirodnog podrijetla u polimerne materijale jer u ovom trenutku nije realno očekivati kompletnu zamjenu tako široko primjenjivanog materijala. Jedno od potencijalnih prirodnih materijala za upotrebu kao navedeno punilo jest komina masline, za koju su provedene mnoge studije. ${ }^{51-53}$

Kod proizvodnje biokompozita izrazito je važna toplinska stabilnost obiju komponenata jer upravo ona određuje procesabilnost i fizičko-mehanička svojstva. Za primjenu komine masline kao punilo provedena je studija S. Lammi $i$ sur. ${ }^{54} \mathrm{Za}$ ispitivanje toplinske stabilnosti provedeni su termogravimetrijski eksperimenti (TGA) u temperaturnom 
rasponu od $20{ }^{\circ} \mathrm{C}$ do $900{ }^{\circ} \mathrm{C}$ pri oksidativnim i inertnim uvjetima. Upotrijebljeni uzorci su prah komine masline dobiven suhim i mokrim postupkom prerade te sirova komina masline. Ustanovljena su različita degradacijska svojstva ovisno o uvjetima. U oba slučaja zabilježen je pad mase u temperaturnom rasponu od $40{ }^{\circ} \mathrm{C}$ do $130{ }^{\circ} \mathrm{C}$, koji je rezultat evaporacije vode. $U$ oksidativnim uvjetima, u kisikovoj atmosferi stabilno temperaturno područje održava se do $200{ }^{\circ} \mathrm{C}$, a od $220{ }^{\circ} \mathrm{C}$ do $380{ }^{\circ} \mathrm{C}$ dolazi do degradacije hemiceluloze, a zatim celuloze. Iznad $400{ }^{\circ} \mathrm{C}$ odvija se oksidacija raspadnute hemiceluloze, celuloze i lignina. U inertnim uvjetima odnosno dušikovoj atmosferi, degradacija hemiceluloze odvija se u temperaturnom rasponu od $150{ }^{\circ} \mathrm{C}$ do $300{ }^{\circ} \mathrm{C}$, a celuloze do $400{ }^{\circ} \mathrm{C}$. Lignin se $\mathrm{u}$ inertnim uvjetima degradira u širokom temperaturnom području do $500{ }^{\circ} \mathrm{C}$. Navedeni rezultati dokaz su da je komina masline toplinski kompatibilna s mnogim polimerima jer je gubitak mase značajan tek iznad temperature od $200{ }^{\circ} \mathrm{C}$, a velik broj polimernih materijala ima nižu temperaturu taljenja $\left(T_{t}\right), n$ np. $T_{t}($ polietilen $)=130-170{ }^{\circ} \mathrm{C}, T_{t}$ (polipropilen $)=165{ }^{\circ} \mathrm{C}, T_{\mathrm{t}}$ (polivinilklorid $)=160-170{ }^{\circ} \mathrm{C}$.

Kod proizvodnje biokompozita izrazito je važno dobiti željena svojstva, a ona su najviše određena afinitetom između matrice i vlakana. Općenito, pri formiranju biokompozita materijali su podvrgnuti četirima mehanizama: segregaciji molekula, kemijskom vezanju, van der Waalsovu vezanju i mehaničkom unutarnjem vezanju. ${ }^{55}$ Glavna prepreka pri stvaranju kompozita jest hidrofilna priroda komine masline i hidrofobna priroda većine polimernih matrica, što rezultira smanjenjem van der Waalsovih interakcija i potencijalno neučinkovitim vezanjem. Međutim, zbog mnogobrojnih fizičkih i kemijskih struktura prisutnih u lignoceluloznom sloju komine masline, postoji širok spektar potencijalno izrazito učinkovitih interakcija, a za njihovo određivanje potrebno je odrediti površinsku energiju komponenata. ${ }^{56}$ $U$ ranije navedenom radu $S$. Lammija $i$ sur. za procjenu površinske energije primijenjen je Owen-Wendt model, a mjereni parametar je kontaktni kut. ${ }^{54}$ Lignocelulozna vlakna imaju površinsku energiju od $29 \mathrm{~mJ} \mathrm{~m}^{-2}$ do $36 \mathrm{~mJ} \mathrm{~m}^{-2}$. Slične vrijednosti zabilježene su i kod drugih autora. ${ }^{56} \mathrm{Na}-$ dalje, zaključeno je da se polarnost povećava s povećanjem površinske energije komponente, odnosno, sa smanjenjem kontaktnog kuta s vodom. Rezultati ukazuju na polarna/ apolarna svojstva kod različito obrađenih komina masline, a na polarnost je utjecala količina celuloze i hemiceluloze u komini. Zaključno, frakcije dobivene suhim procesom i sirova komina pokazuju veće podudaranje s ispitanim polimerima (polipropilen, polietilen, polilaktična kiselina) od podudaranja frakcija dobivenih mokrim postupkom. Također je zaključeno da ispitani uzorci mogu biti komponenta biokompozita bez dodatka aditiva ili modificiranja površine punila. Ključno je odrediti kompatibilne parove punila i matrica.

U istraživanju Kaya i sur. komina masline se dodala kao punilo za polipropilen. ${ }^{57}$ Komina masline dostavljena iz tvrtke Altan (Turska) usitnjena je i dodana u tržišni polipropilen tvrtke Petkim-SOCAR-Turkey. Nakon sušenja i uklanjanja vlage provedena je karakterizacija novostvorenog kompo- zita. Kristaliničnost je znatno porasla s povećanjem udjela komine, kao i otpornost na toplinu, odnosno temperatura dekompozicije se s $382^{\circ} \mathrm{C}$ čistog polipropilena smanjila na $282{ }^{\circ} \mathrm{C}$ u slučaju s $40 \%$ mase komine. Usprkos negativnom učinku smanjenja fleksibilnosti, taj kompozit je ocijenjen kao ekološko i ekonomsko održivo rješenje za zbrinjavanja komine masline.

\section{Zaključak}

U svijetu pa tako i u Hrvatskoj, u sektoru maslinarstva posljednjih se dvadesetak godina bilježi porast proizvodnje maslinova ulja. S obzirom na to da pri proizvodnji maslinova ulja nastaju velike količine otpadne vode kao i krutog otpada, odnosno komine masline koja svojim sastavom toksično djeluje na okoliš, uslijed neadekvatnog odlaganja dolazi do onečišćenja tla i vode. Međutim, komina masline vrijedna je sirovina, a koliko potencijala za iskorištavanje ima prikazuju navedeni primjeri gdje je komina masline prevedena u kozmetičke proizvode, punila za polimere, kompost i energiju.

Povećanje potrošnje fosilnih goriva i iscrpljivanje zaliha ima nepovoljan učinak na okoliš, stoga se razvijaju ekološki i ekonomski prihvatljivi napredni alternativni izvori energije od otpada, u što se ubraja i komina masline. Od komine masline moguće je dobiti energiju na tri načina: anaerobnom digestijom odnosno proizvodnjom bioplina, izravnim izgaranjem u pećima za sagorijevanje biomase te proizvodnjom biodizela od ulja komine masline. Svaki od navedenih procesa ima niz prednosti, ali i nedostataka te do sada nije zaključeno koji od tri načina je ekonomski najisplativiji i ekološki najpovoljniji.

Problem neadekvatnog odlaganja može se riješiti uporabom komine kao komposta za poljoprivredne površine, s obzirom na visok udio organskih i biljnih hranjivih tvari, čime se dobiva visoko kvalitetna kompostna masa koja se primjenjuje za kulture kao što su masline te vinova loza.

Komina masline sadrži visok udio polifenola koji imaju antioksidativno svojstvo zbog čega je moguća primjena u kozmetičkoj industriji. Od komine masline proizvode se razni kozmetički pripravci koji usporavaju starenje kože, a pozitivna praksa zabilježena je i u Hrvatskoj.

Nadalje, otpad komine masline pokazao se kao adekvatno rješenje u polimernoj industriji. Zbog potrebe za štednjom sirovine i odgovarajućih svojstava komine usvojena je praksa primjenjivanja komine kao punila za polimerne materijale. Time nisu narušena svojstva materijala, a uz to se doprinosi smanjenju odlaganja otpada.

Za rješavanje tog problematičnog otpada predloženi su različiti postupci, ali najbolje iskorištenje se može očekivati kombinacijom različitih postupaka. Važno je stoga povezati opisane procese u cjelinu te potpuno iskoristiti potencijal komine masline. 


\section{Popis kratica i simbola List of abbreviations and symbols}

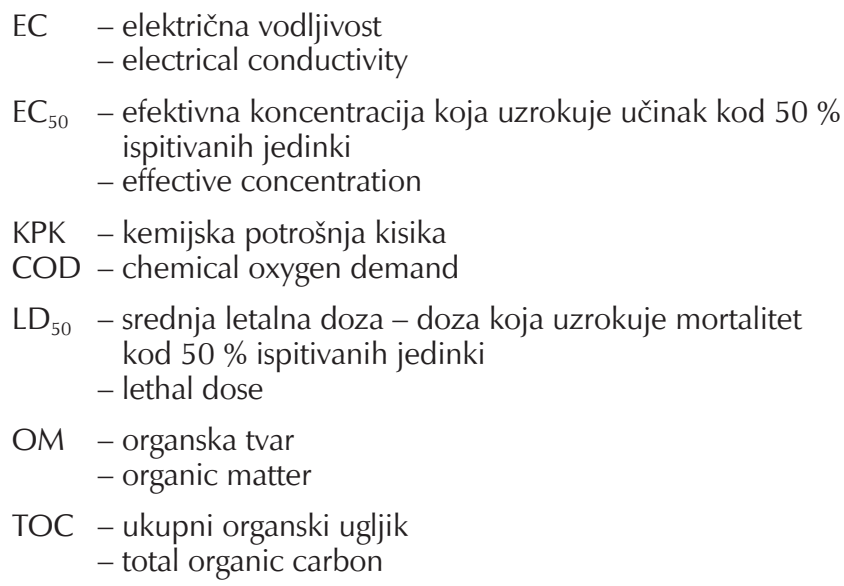

\section{Literatura \\ References}

1. D. Kantoci, Maslina, Glasnik zaštite bilja 6 (2006) 4-14.

2. R. M. Seabra, P. B. Andrade, P. Valentao, M. Faria, A. G. Paice, M. B. P. P. Oliveira, Phenolic profiles of Portuguese Olives: Cultivar and geographics, Olives and Olive Oil in Health and Disease Prevention, Alistair \& Oliveira, 2010., str. 177-186, doi: https://doi.org/10.1016/B978-0-12-374420-3.000206.

3. S. Dermeche, M. C. Larroche, F. Moulti-Mati, P. Michaud, Olive mill wastes: Biochemical characterizations and valorization strategies, Process Biochem. 48 (2013) 1532-1552, doi: https://doi.org/10.1016/j.procbio.2013.07.010.

4. M. I. Covas, Olive oil and the caridovascular system, Pharmacol. Res. 55 (2007) 175-186, doi: https://doi.org/10.1016/j. phrs.2007.01.010

5. O. Koprivnjak, Djevičansko maslinovo ulje: od masline do stola, MIH, Poreč, 2006., str. 7-13.

6. T. Brlek Savić, N. Voća, T. Krička, V. Jurišić, Komina masline kao izvor energije, Glasnik zaštite bilja 3 (2009) 13-18.

7. C. Paredes, J. Cegarra, A. Roig, M. A. Sanchez-Monedero, M. P. Bernal, Characterization of olive-mill wastewater (alpechin) and its sludge for agricultural purposes, Bioresour. Technol. 67 (1997) 111-115, doi: https://doi.org/10.1016/ S0960-8524(98)00106-0

8. N. Azbar, A. Bayram, A. Filibeli, A. Muezzinoglu, F. Sengul, A. Ozer, Review of waste management options in olive oil production, Crit. Rev. Environ. Sci. Technol. 34 (2013) 209247, doi: https://doi.org/10.1080/10643380490279932.

9. URL: https://www.agroportal.hr/maslinarstvo/29554 (1. 4. 2019.).

10. J. A. Alburquerque, J. Gonzalvez, D. Garcia, J. Cegarra, Agrochemical characterisation of "alperujo", a solid by-product of the two-phase centrifugation method for olive oil extraction, Bioresour. Technol. 91 (2004) 195-200, doi: https:// doi.org/10.1016/S0960-8524(03)00177-9.

11. R. Borja, F. Raposo, B. Rincon, Treatment technologies of liquid and solid wastes from two-phase olive oil mills, Grasas y Aceites 57 (2006) 32-46, doi: https://doi.org/10.3989/ gya.2006.v57.i1.20.

12. J. A. Fiestas Ros de Usrinos, R. Borja Padilla, Use and treat- ment of olive mill wastewater: Current situation and prospects in Spain, Grasas y Aceites 43 (1992) 101-106, doi: https://doi.org/10.3989/gya.1992.v43.i2.1182.

13. A. Muscolo, T. Papalia, G. Settineri, F. Romeo, C. Mallama$\mathrm{Ci}$, Three different methods for turning olive pomace in resource: Benefits of the end products for agricultural purpose, Sci. Total Environ. 662 (2019) 1-7, doi: https://doi. org/10.1016/j.scitotenv.2019.01.210.

14. I. A. Pinho, D. V. Lopes, R. C. Martins, M. J. Quina, Phytotoxicity assessment of olive mill wastes and the influence of phenolic compounds, Chemosphere 185 (2017) 258-267, doi: https://doi.org/10.1016/j.chemosphere.2017.07.002.

15. P. Pierantozzi, C. Zampini, M. Torres, M. I. Iska, R. A. Verdenelli, J. M. Meriles, D. Maestri, Physicochemical and toxicological assessment of liquid wastes from olive processing-related industries, J. Sci. Food Agric. 92 (2012) 216-223, doi: https://doi.org/10.1002/jsfa.4562.

16. A. Piotrowska, G. lamarino, M. Antonietta, L. Gianfreda, Short-term effects of olive mill wastewater (OMW) on chemical and biochemical properties of a semiaris Mediterranean soil, Soil Biol. Biochem. 38 (2006) 600-610, doi: https://doi. org/10.1016/j.soilbio.2005.06.012.

17. S. M. Paixao, E. Mendonça, A. Picado, A. M. Anselmo, Acute toxicity evaluation of olive mill wastewaters: a comparative study of three aquatic organisms, Environ. Toxicol. 14 (1999) 263-269, doi: https://doi.org/10.1002/(SICI)15227278(199905)14:2<263::AID-TOX7>3.0.CO;2-D.

18. A. Rouvalis, J. Iliopoulou-Georgudaki, G. Lyberatos, Application of two microbiotests for acute toxicity evaluation of olive mill wastewaters, Fresenius Environ. Bull. 13 (2004) 458-464.

19. I. Karaouzas, E. Cotou, T. A. Albanis, N. T. Skoulikidis, U. Giannakou, Bioassays and biochemical biomarkers for assessing olive mill and citrus processing wastewater toxicity, Environ. Toxicol. 26 (2011) 669-676, doi: https://doi. org/10.1002/tox.20606.

20. L. Beesley, O. Inneh, G. J. Norton, E. Moreno-Jiménez, T. Pardo, R. Clemente, J. J. C. Dawson, Assessing the influence of compost and biochar amendments on the mobility and toxicity of metals and arsenic in a naturally contaminated mine soil, Environ. Pollut. 186 (2014) 195-202, doi: https://doi. org/10.1016/j.envpol.2013.11.026.

21. T. Pardo, P. Bernal, R. Clemente, The use of olive mill waste to promote phytoremediation, Olive mill waste, CSIC, Santiago de Compostela, 2017., str.183-204

22. T. Pardo, R. Clemente, P. Alvarenga, M. P. Bernal, Efficiency of soil organic and inorganic amendments on the remediation of a contaminated mine soil: II. Biological and ecotoxicological evaluation, Chemosphere 107 (2014) 101-108, doi: https://doi.org/10.1016/j.chemosphere.2014.03.017.

23. T. Pardo, R. Clemente, L. Epelde, C. Garbisu, M. P. Bernal, Evaluation of the phytostabilisation efficiency in a trace elements contaminated soil using health indicators, J. Hazard. Mater. 268 (2014) 68-76, doi: https://doi.org/10.1016/j. jhazmat.2014.01.003.

24. T. Pardo, R. Clemente, M. P. Bernal, Effects of compost, pig slurry and lime on trace element solubility and toxicity in two soils differently affected by mining activities, Chemosphere 84 (2011) 642-650, doi: https://doi.org/10.1016/j. chemosphere.2011.03.037.

25. A. Hmid, Z. Al Chami, W. Sillen, A. De Vocht, J. Vangronsveld, Olive mill waste biochar: a promising soil amendment for metal immobilization in contaminated soils, Environ. Sci. Pollut. Res. 22 (2015) 1444-1456, doi: https://doi. 
org/10.1007/s11356-014-3467-6.

26. A. M. Liesch, S. L. Weyers, J. W. Gaskin, K. C. Das, Impact of two different biochars on earthworm growth and survival, Ann. Environ. Sci. 4 (2010) 1-9.

27. D. Li, W. C. Hockaday, C. A. Masiello, P. J. J. Alvarez, Earthworm avoidance of biochar can be mitigated by wetting, Soil Biol. Biochem. 43 (2011) 1732-1737, doi: https://doi. org/10.1016/j.soilbio.2011.04.019.

28. URL: https://hgk.hr/vecer-masline-buducnosti-predstavljanje-projekta-koristenja-komine-masline-u-energetske-svrhe (29. 4. 2019.).

29. O. Al-Ketan, Potential of using olive pomace as a source of renewable energy for electricity generation in the Kingdom of Jordan, J. Renew. Sustain. Energ. 4 (2012) 1-9, doi: https://doi.org/10.1063/1.4769205.

30. A. Roig, M. L. Cayuela, M. A. Sanchez-Monedero, An overview on olive mill wastes and their valorisation methods, Waste Manage. 26 (2006) 960-969, doi: https://doi. org/10.1016/j.wasman.2005.07.024.

31. M. A. Rajaeifar, A. Akram, B. Ghobadian, S. Rafiee, R. Heijungs, M. Tabatabaei, Environmental impact assessment of olive pomace oil biodiesel production and consumption: A comparative lifecycle assessment, Energy 106 (2016) 87102, doi: https://doi.org/10.1016/j.energy.2016.03.010.

32. P. E. Tsakiridis, M. Samouhos, M. Perraki, Valorization of Dried Olive pomace as an alternative fuel resource in cement clinkerization, Constr. Build. Mater. 153 (2017) 202-210, doi: https://doi.org/10.1016/j.conbuildmat.2017.07.102.

33. E. Christoforou, P. A. Fokaides, A review of olive mill solid wastes to energy utilization techniques, Waste Manage. 49 (2016) 346-363, doi: https://doi.org/10.1016/j.wasman.2016.01.012.

34. A. R. Tekin, A. Coskun Dalgıc, Biogas production from olive pomace, Resour. Conserv. Recycl. 30 (2000) 301-313, doi: https://doi.org/10.1016/S0921-3449(00)00067-7.

35. M. Milanese, A. De Risi, A. De Riccardis, D. Laforgia, Numerical study of anaerobic digestion system for olive pomace and mill wastewater, Energy procedia 45 (2014) 141-149, doi: https://doi.org/10.1016/j.egypro.2014.01.016.

36. T. Ergüder, E. Güven, G. Demirer, Anaerobic treatment of olive mill wastes in batch reactors, Process Biochem. 36 (2000) 243-248, doi: https://doi.org/10.1016/S00329592(00)00205-3.

37. URL: http://www.mppi.hr/default.aspx?id=21836 (29. 4. 2019.).

38. A. Lama-Munoz, P. Alvarez-Mateos, G. Rodríguez-Gutierrez, M. Montana Dur, J. Fernandez-Bola, Biodiesel production from olive epomace oil of steam-treated alperujo, Biomass Bioenerg. 67 (2014) 443-450, doi: https://doi.org/10.1016/j. biombioe.2014.05.023.

39. J. Ryckeboer, J. Mergaert, J. Coosemans, K. Deprins, J. Swings, Microbiological aspects of biowaste during composting in a monitored compost bin, J. Appl. Microbiol. 94 (2003) 127-137, doi: https://doi.org/10.1046/j.13652672.2003.01800.x.

40. A. K. M. Muktadirul Bari Chowdhury, C. S. Akratos, D. V. Vayenas, S. Pavlou, Olive mill waste composting: A review, Int. Biodeterior. Biodegrad. 85 (2013) 108-119, doi: https://doi. org/10.1016/j.ibiod.2013.06.019.

41. J. M. Agnew, J. J. Leonard, The physical properties of compost, Compost Sci. Util. 1 (2003) 238-264, doi: https://doi. org/10.1080/1065657X.2003.10702132.

42. G. Ait Baddi, J. Cegarra, G. Merlina, J. C. Revel, M. Hafidi, Qualitative and quantitative evolution of polyphenolic com- pounds during composting of an olive-mill waste-WS mixture, J. Hazard. Mater. 165 (2009) 1119-1123, doi: https:// doi.org/10.1016/j.jhazmat.2008.10.102.

43. C. Paredes, M. P. Bernal, J. Cegarra, A. Roig, Bio-degradation of olive mill wastewater sludge by its co-composting with agricultural wastes, Bioresour. Technol. 85 (2002) 1-8, doi: https://doi.org/10.1016/S0960-8524(02)00078-0.

44. P. Viola, M. Viola, Virgin olive oil as a fundamental nutritional component and skin protector, Clin. Dermatol. 27 (2009) 159-165, doi: https://doi.org/10.1016/j.clindermatol.2008.01.008.

45. M. Elleuch, D. Bedigian, O. Roiseux, S. Besbes, C. Blecker, H. Attia, Dietary fibre and fibre-rich-by-products of food processing: characterisation, technological functionality and commercial applications: a review, Food Chem. 124 (2011) 411-421, doi: https://doi.org/10.1016/j.foodchem.2010.06.077.

46. G. Rodriguez-Gutierrez, F. Rubio-Senent, A. Lama-Munoz, A. Garcia, J. Fernandez-Bolanos, Properties of lignin, cellulose, and hemicelluloses isolated from olive cake and olive stones: binding of water, oil, bile acids, and glucose, J. Agric. Food Chem. 62 (2014) 8973-8981, doi https://doi.org/10.1021/ jf502062b.

47. N. Jurman, HR P20140850 B3, Hrvatski glasnik intelektualnog vlasništva 24, 10/2017.

48. V. Hasirci, P. Yilgor, T. Endogan, G. Eke, N. Hasirci, Polymer fundamentals: Polymer Synthesis, Compr. Biomater. 1 (2011) 349-371, doi: https://doi.org/10.1016/B978-0-08055294-1.00034-9.

49. M. F. Maitz, Applications of synthetic polymers in clinical medicine, Biosurf. Biotribol. 1 (2015) 161-176, doi: https:// doi.org/10.1016/j.bsbt.2015.08.002.

50. A. Malinauskas, Chemical deposition of conducting polymers, Polymer 42 (2001) 3957-3972, doi https://doi. org/10.1016/S0032-3861(00)00800-4.

51. M. Delgado-Aguilar, Q. Tarres, M. A. Peach, P. Mutje, P. Fullana-I-Palmer, Are cellulose nanofibers a solution for a more circular economy of paper products?, Environ. Sci. Technol. 49 (2015) 12206-12213, doi: https://doi.org/10.1021/acs. est. 5 b02676.

52. T. Stock, G. Seliger, Opportunities of sustainable manufacturing in industry, Procedia CIRP 40 (2016) 536-541, doi: https://doi.org/10.1016/j.procir.2016.01.129.

53. P. Srinivasan, A. K. Sarmah, R. Smernik, O. Das, M. Farid, W. Gao, A feasibility study of agricultural and sewage biomass as biochar, bioenergy and biocomposite feedstock: Production, characterization and potential applications, Sci. Total Environ. 215 (2015) 495-505, doi: https://doi.org/10.1016/j. scitotenv.2015.01.068.

54. S. Lammi, A. Barakat, C. Mayer-Laigle, D. Djenane, N. Gontard, H. Angellier-Coussy, Dry fraction of olive pomace as a sustainable process to produce fillers for biocomposites, Powder Technol. 326 (2018) 44-53, doi: https://doi. org/10.1016/j.powtec.2017.11.060.

55. J. K. Kim, Y. W. Mai, Engineered Interfaces in Fiber Reinforced Composites, $1^{\text {st }}$ Edition, 1998.

56. M. A. Berthet, H. Angellier-Coussy, V. Guillard, N. Gontard, Vegetal fiber-based biocomposites: which stakes for food packaging applications?, J. Polym. Sci. 133 (2016) 1-18, doi: https://doi.org/10.1002/app.42528.

57. N. Kaya, M. Atagur, O. Akyuz, M. Seki, M. Sarikanat, M. Sutcu, M. O. Seydibeyoglu, K. Sever, Fabrication and characterization of olive pomace filled PP composites, Composites Part B 150 (2017) 277-283, doi: https://doi.org/10.1016/j. compositesb.2017.08.017. 


\section{SUMMARY}

\section{The Influence of Olive Pomace on the Environment \\ Dajana Kučić Grgić, a* Matea Gavran, ${ }^{a}$ Kristina Miškić,a Ana Škunca, and Vesna Ocelić Bulatovićb}

Olive pomace is a residue substance in the food industry. It is not considered a hazardous waste or even a waste in general. This is potentially problematic because olive pomace contains certain compounds that can have a negative impact on the ecosystem, especially on aquatic organisms and plants. In case of inappropriate disposal, these toxic compounds may be leached into the soil and groundwater. This topic attracts additional interest due to the potential of olive pomace. Nowadays, olive pomace can be used for various purposes, which are a frequent subject of a lot of scientific research.

\section{Keywords}

Olive pomace, waste, toxicity, raw material

a Faculty of Chemical Engineering and

Review

Technology, Croatia

${ }^{\mathrm{b}}$ Faculty of Metallurgy, University of Zagreb,

Croatia 